\title{
Early patterns of functional brain development associated with autism spectrum disorder in tuberous sclerosis complex.
}

Abigail Dickinson ${ }^{1}$, Kandice J. Varcin², Mustafa Sahin ${ }^{3}$, Charles A. Nelson III ${ }^{4}$, Shafali S. Jeste ${ }^{1}$.

1. UCLA Semel Institute of Neuroscience and Human Behavior, David Geffen School of Medicine, 760 Westwood Plaza, Los Angeles, CA, 90095.

2. Telethon Kids Institute, University of Western Australia, 100 Roberts Road, Subiaco, WA, 6008, Australia.

3. Department of Neurology, Boston Children's Hospital, Translational Neuroscience Center, 300 Longwood Avenue, Boston, MA, 02115.

4. Division of Developmental Medicine, Boston Children's Hospital, Harvard Medical School \& Harvard Graduate School of Education, Harvard University, 1 Autumn Street, Boston, MA, 02215.

\section{Acknowledgements}

The authors wish to thank all of the infants and families who generously participated in the study. The present research was supported by grants from the Department of Defense (DOD CDMRP TSCRP: 2011-2014) and the UCLA CTRC (UL1TR000124). The authors are also grateful to Scott Huberty and Lauren Baczewski for their role in the study, and to Manjari Daniel for her helpful comments on the manuscript.

\begin{abstract}
Tuberous sclerosis complex (TSC) is a rare genetic disorder that confers a high risk for autism spectrum disorders (ASD), with behavioral predictors of ASD emerging early in life. Deviations in structural and functional neuronal connectivity are highly implicated in both TSC and ASD.
\end{abstract}

For the first time, we explore whether electroencephalographic (EEG) measures of network function precede or predict the emergence of ASD in TSC. We determine whether altered brain function (1) is present in infancy in TSC, (2) differentiates infants with TSC based on ASD diagnostic status, and (3) is associated with later cognitive function.

We studied 35 infants with TSC $(N=35)$, and a group of typically developing infants $(n=20)$ at 12 and 24 months of age. Infants with TSC were later subdivided into ASD and non-ASD groups based on clinical evaluation. We measured features of spontaneous alpha oscillations $(6-12 \mathrm{~Hz})$ that are closely associated with neural network development: alpha power, alpha phase coherence (APC) and peak alpha frequency (PAF).

Infants with TSC demonstrated reduced interhemispheric APC compared to controls at 12 months of age, and these differences were found to be most pronounced at 24 months in the infants who later developed ASD. Across all infants, PAF at 24 months was associated with verbal and non-verbal cognition at 36 months.

Associations between early network function and later neurodevelopmental and cognitive outcomes highlight the potential utility of early scalable EEG markers to identify infants with TSC requiring additional targeted intervention initiated very early in life.

] 


\section{Introduction}

Tuberous sclerosis complex (TSC) is a rare autosomal-dominant genetic syndrome caused by the inactivation of TSC1 or TSC2 genes. The TSC1/TSC2 protein complex plays a critical role in regulating cell growth and proliferation via mechanistic target of rapamycin (mTOR) signaling. In TSC, MTOR remains constitutively active, resulting in unrestricted cell growth and proliferation throughout the body. While TSC is considered a multisystem disorder (affecting the kidneys, heart, eyes, lungs, and skin), the central nervous system is consistently and prominently affected (Curatolo, Bombardieri, \& Jozwiak, 2008). The majority of individuals with TSC have hamartomas in the brain, including cortical tubers, subependymal nodules and/or subependymal giant-cell astrocytomas (Northrup, Krueger, \& International Tuberous Sclerosis Complex Consensus Group, 2013; Roth et al., 2013), with prevalence estimates of epilepsy up to $90 \%$ (Chu-Shore, Major, Camposano, Muzykewicz, \& Thiele, 2010; Devlin, Shepherd, Crawford, \& Morrison, 2006). Neurodevelopmental or neuropsychiatric disorders (referred to as TSC-associated neuropsychiatric disorders [TAND]; (de Vries et al., 2015; Leclezio, Jansen, Whittemore, \& de Vries, 2015)) are common. 25-60\% of children with TSC will receive a diagnosis of Autism Spectrum Disorder (ASD) (Capal et al., 2017; Granader et al., 2010; Jeste, Sahin, Bolton, Ploubidis, \& Humphrey, 2008; Vignoli et al., 2015), and more than $50 \%$ have some degree of cognitive impairment (Curatolo, Moavero, \& de Vries, 2015; Joinson et al., 2003).

TSC is often diagnosed in utero or shortly after birth through identification of either cardiac or cortical hamartomas (Datta, Hahn, \& Sahin, 2008; Davis et al., 2017), facilitating the examination of these infants well before diagnoses of ASD or intellectual disability (ID) are made. Longitudinal studies have revealed early behavioral differences between infants and toddlers with TSC who later receive an ASD diagnosis and those who do not (Jeste et al., 2016; McDonald et al., 2017). Infants who develop ASD are found to demonstrate social communication deficits by 9 months of age (McDonald et al., 2017) and lower cognitive function by 12 months of age. Interestingly, toddlers not diagnosed with ASD demonstrate social communication profiles indistinguishable from typically developing (TD) children, despite having comparable cortical tuber burden and epilepsy severity to those with ASD (Jeste et al., 2014). Given the high risk of neurodevelopmental disorders in TSC, with symptoms emerging in infancy, we asked whether there are neurobiological markers of atypical brain development that relate to and predict neurodevelopmental disorders in TSC.

Commensurate with our understanding of the neurobiological mechanisms underlying neurodevelopmental disorders as a whole (Geschwind \& Levitt, 2007; Jeste, Frohlich, \& Loo, 2015), it is most likely that altered patterns of neuronal connectivity (outside of cortical tubers, subependymal nodules and astrocytomas) account for atypical neurodevelopment in TSC (Ebrahimi-Fakhari \& Sahin, 2015; Jülich \& Sahin, 2014; Peters et al., 2012). The critical role of TSC1/2 proteins in neuronal connectivity is supported by evidence from preclinical studies that demonstrate abnormalities in neuronal migration and morphology (Knox et al., 2007; Nie et al., 2010), synaptic plasticity and function (Ehninger et al., 2008; Zeng et al., 2007), excitation-inhibition balance (Bateup et al., 2013), and myelination patterns (Ercan et al., 2017) in the context of a TSC mutation. In addition, structural imaging studies in individuals with TSC demonstrate widespread alterations in structural connections (Baumer et al., 2015; Krishnan et al., 2010; Lewis et al., 2012; Peters et al., 2012, 2012), relevant to the variability seen in neurodevelopmental outcomes. Using an unbiased whole-brain connectivity analysis, Im et al. (2016) identified altered structural connectivity in TSC with markedly reduced inter-hemispheric connectivity (aged 3-24 years) compared to a control sample, most prominent in those with developmental delay (Im et al., 2015). Similarly, deficits in the integrity of white matter microstructure are found to be more pronounced in individuals with TSC who also have an ASD diagnosis (Baumer et al., 2017; Lewis et al., 2012; Peters et al., 2012). Finally, and highly relevant to the present study, a pattern of functional hypo-connectivity is identified using electroencephalography (EEG) in individuals with TSC across a wide age range, with hypoconnectivity (in some cortical areas) more prominent in individuals with both TSC and ASD (Peters et al., 2013)..

EEG offers a scalable and feasible method to capture the specific changes in brain dynamics that occur during infancy. EEG measures brain function in three important dimensions: space, time and frequency (Kida, Tanaka, \& Kakigi, 2016). Here we focus on oscillations which occur within the alpha range $(6-12 \mathrm{~Hz})$, which represent the dominant signal in taskindependent environments (Guggisberg et al., 2008), and have been well-characterized during early infancy (Saby \& Marshall, 2012). In addition to measuring the power of alpha oscillations, we focus on two measures of alpha activity, 
alpha phase coherence (APC) and peak alpha frequency (PAF), that are specifically sensitive to changes in neuronal connectivity that occur over the course of typical brain maturation, and in clinical populations. Across the oscillatory signals that co-ordinate large scale neural communication, the coherence of neural signals in the alpha range, APC, is demonstrated to be the most sensitive to both the healthy development of (Smit et al., 2012), and disruptions to (Hinkley et al., 2011), functional and structural connectivity. Similarly, the frequency at which maximal power occurs within the alpha band, PAF, shows well-characterized increases with chronological age in TD children (Chiang, Rennie, Robinson, van Albada, \& Kerr, 2011; Cragg et al., 2011; Dustman, Shearer, \& Emmerson, 1999; Miskovic et al., 2015; Somsen, van't Klooster, van der Molen, van Leeuwen, \& Licht, 1997; Stroganova, Orekhova, \& Posikera, 1999). In ASD, PAF relates to cognitive function, not age (Dickinson, DiStefano, Senturk, \& Jeste, 2017). In addition to age and cognition, both APC and PAF are associated with white matter architecture (axon growth and myelination) (Jann et al., 2012; Teipel et al., 2009), further suggesting that these metrics index the development of neural networks (Wolfgang Klimesch, Sauseng, \& Hanslmayr, 2007; Valdés-Hernández et al., 2010).

As part of a longitudinal study of TSC, we utilized high-density EEG measures of spontaneous alpha oscillations to characterize the development of functional connectivity across first two years of life and to determine whether these early biomarkers informed neurodevelopmental outcomes. More specifically, we asked: 1) Do alpha oscillations (power, PAF and PAC) differ between infants with and without TSC?; (2) Do alpha oscillations (power, PAF and PAC) differentiate infants with TSC who develop ASD from those that do not?; and 3) Does PAF measured during infancy predict later cognitive function? Data from this study could reveal the earliest manifestations of atypical brain development that may precede and predict the development of ASD and ID in TSC. Such investigations can help elucidate mechanisms underlying the distinct (and often diverse) neurodevelopmental outcomes in TSC, identify early predictive biomarkers of neurodevelopmental disorders, further stratify infants by risk for neurodevelopmental disorders, and provide objective measures of change with early intervention in high-risk infants.

\section{Participants}

\section{Method}

Infants were enrolled in a longitudinal, two-site study examining early development in TSC (Jeste et al., 2016, 2014; McDonald et al., 2017). Infants with confirmed TSC diagnoses (Northrup et al., 2013) were recruited through specialty clinics, newborn nurseries, pediatricians' offices and the Tuberous Sclerosis Alliance. TD control infants (described below) were recruited through institutional review board-approved databases.

Infants visited one of the two study sites throughout the first two years of life (at 6, 9, 12 and/or 24 months of age) to undergo EEG recording. At 18, 24 and/or 36 months, infants underwent behavioral assessments to determine ASD symptoms (described in detail below), which was followed by a Best Clinical Estimate diagnostic process. A schematic diagram of the study protocol can be found in the supplementary materials. Although we collected EEG data in a small subset of infants at age 6 and 9 months, in order to achieve adequate sample sizes to interrogate statistical differences between groups, we focused on 12 and 24 month time points.

To be included in the present analyses, participants had to have EEG data for at least one of the two time points (12 and 24 months). Exclusion criteria for TD infants included prematurity ( $<37$ weeks gestational age), birth trauma, developmental concerns, or a first-degree relative with ASD or ID. It should be noted that while 'typically developing' may not traditionally be used to describe infants, our later follow-up time points were used to confirm that no developmental concerns were present in the TD group at 36 months of age. The study received ethical approval from both study sites. Parents provided informed written consent, in accordance with the Declaration of Helsinki.

TD ( $N=22)$ and TSC ( $N=36)$ infants completed an EEG recording session at 12 or 24 months. Of this sample, 2 TD participants and 1 TSC participant were excluded from the current analyses due to extensive EEG artifact. Final groups therefore consisted of 35 TSC (12 months: $n=18 ; 24$ months: $n=28$ ), and 20 TD infants (12 months: $n=20 ; 24$ months: $n=12)$. Clinical genetics reports were available for $n=21$ (60\%) of the total TSC sample, with all TSC infants meeting 
clinical criteria for TSC (Northrup et al., 2013). Demographic and developmental information for the sample is summarized in Table 1.

It should be noted that males were over-represented in the TSC group. While it has been shown that many behavioral features (including the presence of ASD and ID) are distributed equally across both sexes in TSC (Curatolo, Porfirio, Manzi, \& Seri, 2004; de Vries, Hunt, \& Bolton, 2007), larger samples in the future (described in the discussion) will allow the exploration of sex-related differences in early brain function in TSC.

Table 1. Demographic participant information.

\begin{tabular}{|c|c|c|c|c|}
\hline & $\begin{array}{l}\text { TD Control } \\
\qquad(n=20)\end{array}$ & $\begin{array}{c}\text { TSC } \\
(n=35)\end{array}$ & $\begin{array}{l}\text { ASD- } \\
(n=14)\end{array}$ & $\begin{array}{l}\text { ASD+ } \\
(n=17)\end{array}$ \\
\hline $\begin{array}{c}\text { Sex } \\
\text { Number female (\% female). }\end{array}$ & $11 \mathrm{f}(55 \%)$ & $9 \mathrm{f}(26 \%)$ & $4 \mathrm{f}(29 \%)$ & $4 \mathrm{f}(24 \%)$ \\
\hline $\begin{array}{l}12 \text { Month EEG } \\
\text { Number completed (percentage } \\
\text { completed). }\end{array}$ & $n=20(100 \%)$ & $n=18(51 \%)$ & $\mathrm{N}=7(50 \%)$ & $n=8(47 \%)$ \\
\hline $\begin{array}{l}24 \text { Month EEG } \\
\text { Number completed (percentage } \\
\text { completed). }\end{array}$ & $\mathrm{n}=12(60 \%)$ & $n=28(80 \%)$ & $n=13(93 \%)$ & $n=14(82 \%)$ \\
\hline $\begin{array}{c}36 \text { Months Verbal DQ } \\
\text { Mean (SD); Number completed } \\
\text { (percentage completed) }\end{array}$ & $\begin{array}{l}M=115.20 \\
(S D=30.68) \\
n=10(50 \%)\end{array}$ & $\begin{array}{c}M=68.92 \\
(S D=30.38) \\
n=23(66 \%)\end{array}$ & $\begin{array}{c}M=82.74 \\
(S D=22.57) \\
n=14(100 \%)\end{array}$ & $\begin{array}{c}M=47.42 \\
(S D=29.25) \\
n=9(53 \%)\end{array}$ \\
\hline $\begin{array}{l}36 \text { Months Non-Verbal DQ } \\
\text { Mean (SD); Number completed } \\
\text { (percentage completed) }\end{array}$ & $\begin{array}{l}M=113.87 \\
(S D=24.34) \\
n=10(50 \%)\end{array}$ & $\begin{array}{c}M=73.32 \\
(S D=24.27) \\
n=23(66 \%)\end{array}$ & $\begin{array}{c}M=84.40 \\
(S D=20.78) \\
n=14(100 \%)\end{array}$ & $\begin{array}{l}M=56.09 \\
(S D=19.24) \\
n=9(53 \%)\end{array}$ \\
\hline $\begin{array}{c}\text { ASD Outcome } \\
\text { Mean Calibrated severity score } \\
\text { (SD); Number completed } \\
\text { (percentage completed) }\end{array}$ & $\begin{array}{c}M=1.05 \\
(S D=0.52) \\
n=19(95 \%)\end{array}$ & $\begin{array}{c}M=4.3 \\
(S D=2.77) \\
n=30(86 \%)\end{array}$ & $\begin{array}{c}M=1.71 \\
(S D=.82) \\
n=14(100 \%)\end{array}$ & $\begin{array}{c}M=6.24 \\
(S D=2.05) \\
n=17(100 \%)\end{array}$ \\
\hline
\end{tabular}

\section{Seizures, Tubers \& Medication}

Thirty-two (91\%) of participants with TSC had seizure data available through parent-report and/or medical records. Of these individuals, the majority (29/32; 91\%) had seizures. Age of onset ranged from day of birth to 22 months, with a median age of onset at 4 months (interquartile range $=4.56$ months). Of those with seizures, $62.5 \%(20 / 32)$ had infantile spasms. Information regarding the presence of cortical tubers was present for $80 \%$ of the TSC sample $(n=28)$. Of the participants with available tuber information, $28(100 \%)$ had tubers evident on clinical MRI. Of infants with available medication information (26/32; 81\%), 92\% (24/26) had taken antiepileptic medications (AEDs) at either the 9, 12, and/or 24 month assessments. Only the 2 infants with TSC who had no history of seizures were naïve to AEDs. No history of seizures or medication use were reported for any TD infant. See supplementary tables S1 and S2 for additional details regarding seizure history and medication.

\section{Behavioral assessments}

\section{Autism symptoms and diagnosis}


Clinical ASD symptoms were assessed using Modules 1 and 2 of the Autism Diagnostic Observation Schedule (ADOS; (Lord et al., 2000). Calibrated severity scores (CSS) were calculated in order to facilitate comparison of scores across modules (Gotham, Risi, Pickles, \& Lord, 2007). A diagnostic outcome of ASD (ASD+) was based on both meeting the ADOS cut-off score for ASD (CSS $\geq 4$ ), and a clinical best estimate judgement carried out by a trained clinician. Infants with TSC who did not show elevated ASD symptoms are described as ASD-.

Nineteen (95\%) TD infants underwent an ADOS assessment. These were carried out at either 18 ( $n=3 ; 15.8 \%), 24$ ( $n=6$; $31.6 \%$ ) or 36 months ( $n=10 ; 52.6 \%)$. No TD infants met criteria for ASD. Of the 36 TSC infants included in the present study, 4 (11\%) did not complete an ADOS assessment. These infants were included in the main group comparison (TSC compared to TD infants) but not included in any sub-analyses of ASD+ compared to ASD-. Of the four children with TSC who did not complete an ADOS assessment, one could not have the ADOS administered in their native language, and three were lost to follow-up. Of the 31 TSC infants that received an ADOS assessment at either $18(n=1 ; 3 \%), 24$ ( $n=6$; $19 \%$ ) or 36 months ( $n=24 ; 77 \%), 17$ were deemed to have met ASD criteria based on Best Clinical Estimate (55\%), and 14 did not (45\%). This is consistent with previously reported prevalence rates of ASD in TSC (Jeste et al., 2008).

\section{Cognitive Function}

Cognitive function was assessed at 36 months of age using a standardized measure of cognitive and motor development, the Mullen Scales of Early Learning (MSEL; (Mullen, 1995). A verbal developmental quotient (VDQ) was calculated using the average age equivalent score of the Receptive Language and Expressive Language subscale scores (divided by chronological age), and a non-verbal developmental quotient (NVDQ) was calculated using the average age equivalent score of the Visual Reception and Fine Motor subscale scores (divided by chronological age) (Akshoomoff, 2006). Cognitive function measures were only available for $50 \%$ of the TD group and $66 \%$ of the TSC group, due to a large number of participants being lost to follow up before cognitive function was assessed at 36 months (see Table 1).

\section{EEG Acquisition and Processing}

\section{EEG Recording}

Continuous EEG data were recorded using a high density 128-channel HydroCel Geodesic Sensor Net (Electrical Geodesics Inc., Eugene, OR). EEG was recorded for five minutes in a dark, sound-attenuated room while infants sat in their caregiver's lap. Consistent with many other studies in developmental populations, a research assistant aimed to keep the infant settled and content for the duration of the recording by blowing bubbles (Dawson et al. 1995; McEvoy et al. 2015; Stroganova et al. 1999; Tierney et al. 2012; Webb et al. 2015; Gabard-Durnam, 2015; Levin, 2017). Net Station 4.4.5 software was used to record from a Net Amps 300 amplifier with a low-pass analog filter cutoff frequency of $6 \mathrm{KHz}$. Data were sampled at $500 \mathrm{~Hz}$ and referenced to vertex at the time of recording. Electrode impedances were kept below $100 \mathrm{~K} \Omega$.

\section{EEG Data Pre-processing}

All offline data processing and analyses were performed using EEGLAB (Delorme \& Makeig, 2004), and in-house MATLAB scripts. Data were high pass filtered to remove frequencies below $1 \mathrm{~Hz}$ and low pass filtered to remove frequencies above $50 \mathrm{~Hz}$, using a finite impulse response filter implemented in EEGLAB. Continuous data were then visually inspected, and noisy channels were removed. Following channel removal, data were interpolated to the international 10-20 system 25 channel montage (Jasper, 1958). Sections of data that showed electromyogram (EMG) or other nonstereotyped artifacts, based on visual inspection of the signal, were then removed from the recording. Independent component analysis (ICA), a statistical blind source separation technique (Makeig, Jung, Bell, Ghahremani, \& Sejnowski, 1997), was implemented to remove electrooculogram (EOG) and other stereotyped artifacts from the data. After decomposing the data into maximally independent components (IC), the scalp topography and time course of each IC was visually inspected. Any IC that represented a non-neural source (including EMG, EOG and line noise) was removed from the data. The experimenter was blinded to all participant details throughout the data cleaning process. 
Data were then separated into three-second epochs. The minimum amount of artifact free data available across participants was 46 seconds, thus the first 45 seconds ( 15 epochs) of data from every participant underwent analyses. This data length represents an appropriate minimum threshold to gain reliable estimates of the characteristics of spontaneous EEG (Dickinson et al., 2017; Gudmundsson, Runarsson, Sigurdsson, Eiriksdottir, \& Johnsen, 2007).

\section{EEG data processing: Alpha Power}

Welch's method, implemented using 2-second Hamming windows with $50 \%$ overlap, was used to compute spectral power from cleaned EEG for each of the 25 electrodes. The resulting power spectra had approximately $0.5 \mathrm{~Hz}$ frequency resolution. Relative power was calculated for each region of interest by determining the proportion of total spectral power $(1-50 \mathrm{~Hz})$ accounted for by each frequency bin. Relative power values were then summed for frequencies within the alpha $(6-12 \mathrm{~Hz})$ range.

\section{EEG data Processing: Peak Alpha Frequency (PAF)}

PAF was computed for three regions of interest using the computed power spectra (described above) from six channels (F3, F4, C3, C4, $\mathrm{O} 1$ and $\mathrm{O} 2$ ), with each region defined by averaging the power spectra from two channels (i.e., F3, F4 = frontal; C3, C4 = central; O1, O2 = occipital). A robust curve fitting procedure (fully described in Dickinson et al., 2017) was used to quantify peak alpha frequency in an objective manner that is free of bias towards lower frequencies (Neto, Allen, Aurlien, Nordby, \& Eichele, 2015). If the curve-fitting procedure failed, data were omitted from further analysis. Chi-square analyses revealed that there were no group differences in peak presence between TSC and TD groups, with $9.63 \%$ of participants at 12 months, and $3.3 \%$ of participants at 24 months having at least one region omitted from analysis.

\section{EEG data processing: Alpha Phase Coherence (APC)}

Cleaned EEG data underwent surface Laplacian transform using realistic head geometry, based on the average head radius of participants in the present sample ( 12 months $=7.3 \mathrm{~cm} ; 24$ months $=7.8 \mathrm{~cm}$ ). The surface Laplacian is the second spatial derivative of the scalp recorded potentials for each electrode, thus transforming the scalp-recorded EEG into estimates of current source density (CSD). We employed a spline flexibility constant of $m=3$, which represents adequate flexibility to prevent distortion of the original data (Kayser \& Tenke, 2015).

Coherence analyses were then conducted on CSD values. CSD values were decomposed into frequency-time domain using Fast Fourier Transform with a fixed window size of 1024 samples to generate a sequence of amplitude and phase components for the frequency bins between $6-12 \mathrm{~Hz}$. Due to the hypothesis of the present study, coherence analysis was restricted to the alpha range, defined here as $6-12 \mathrm{~Hz}$, a commonly used range in young children (McLaughlin, Fox, Zeanah, \& Nelson, 2011; Oberman, Ramachandran, \& Pineda, 2008).

Coherence was then computed in the form of event-related phase coherence (ERPCOH) from the aforementioned resting state epochs using the newcrossf function provided by EEGLAB (Delorme \& Makeig, 2004). For each channel pair, phase coherence value was calculated by averaging ERPCOH of all latencies and of all the frequency bins encompassed by alpha band, resulting in 300 unique average alpha coherence values for every possible electrode pair.

\section{Statistical Analysis}

In order to retain participants who only contributed EEG at one time point, analyses of EEG differences were conducted separately at 12 and 24 months of age. 
Two main group comparisons were performed: (1) TSC vs TD (2) ASD+ vs ASD-. As a reminder, all infants included in ASD group comparison had a TSC diagnosis. Identical analysis approaches (described below) were used for both of the group comparisons. Due to the large number of comparisons, type I errors were controlled using false discovery rate (FDR) methods (Benjamini \& Hochberg, 1995). While uncorrected $P$ values are reported throughout the results section for ease of interpretation, results are only determined to be (and described as) significant if they remained so following FDR correction (FDR=0.1). For any significant group contrasts, we confirmed that the relevant measurement values did not vary across acquisition sites $(\mathrm{P}<0.05)$.

Power: Instead of selecting predefined regions of interest, we took an unbiased, data-driven approach to examine power across the entire scalp. Group differences (in all 25 electrodes), were examined using test statistics which represented normalized differences in group means. A permutation test, where group labels were randomly assigned to subjects in each resample, was used to estimate the distribution of the test statistics. Two separate permutation tests (100,000 permutations each) were used to study group differences at 12 and 24 months.

PAF: Two separate repeated measure ANCOVA's (with site entered as a covariate) were used to determine whether there were group differences in PAF at 12 and 24 months. To include all possible data and study regional differences, each region was investigated separately in follow-up analyses.

APC: We also applied non-parametric permutation testing to study group differences in APC. We examined APC for every possible electrode pair combination across the scalp (300 electrode pairs). Group differences in APC were examined using two separate permutation tests (described above) at 12 and 24 months.

\section{Statistical Analysis: PAF and Cognitive Function}

In order to maximize both sample size and range of cognitive function, correlations between cognitive function and PAF were collapsed across all infants (TD \& TSC). A non-parametric Kendall's tau correlation was employed to examine relationships between cognitive function and PAF for each separate region of interest (frontal, central \& occipital), so as to make no assumptions about the distribution of the data.

\section{Results}

\section{TSC/TD group comparison.}

Alpha Power: There were no alpha power differences between TSC and TD infants at 12 months $(P>0.39)$ or 24 months $(P>0.005)$.

PAF: At 12 months, there was no significant effect of group $(F(1,27)=2.322, P=.139)$, or region $(F(2,54)=.379, P=.69)$, and no group $x$ region interaction effect $(F(2,54)=.257, P=.774)$ on PAF. At 24 months, there was a significant effect of group $(F(1,34)=5.909, P=.020)$, where PAF values were significantly lower in the TSC group compared to the TD group. There was also a significant effect of region $(F(2,68)=3.549, P=.034)$, but no group $x$ region interaction effect $(F(2,68)=.042$, $\mathrm{P}=.959)$. PAF values for each region of interest are described in Table 2.

APC: At 12 months, infants with TSC ( $M=.24, S D=.03)$ showed significantly decreased APC compared to TD infants $(\mathrm{M}=.31, \mathrm{SD}=.09)$ for a long-range temporal interhemispheric connection between electrodes $\mathrm{T7}$ and $\mathrm{C} 4(\mathrm{P}<0.00013)$. There were no differences in APC for this connection between the two sites of acquisition ( $P>.232)$. At 24 months, there were no significant differences in APC $(P>0.002)$. 
A)

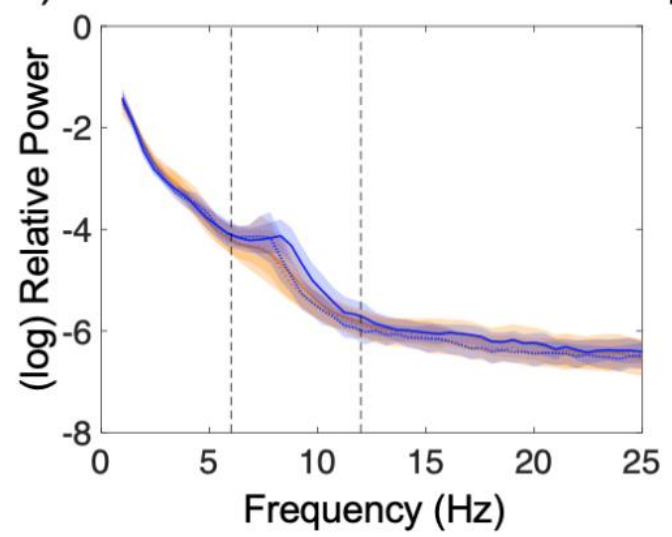

B)

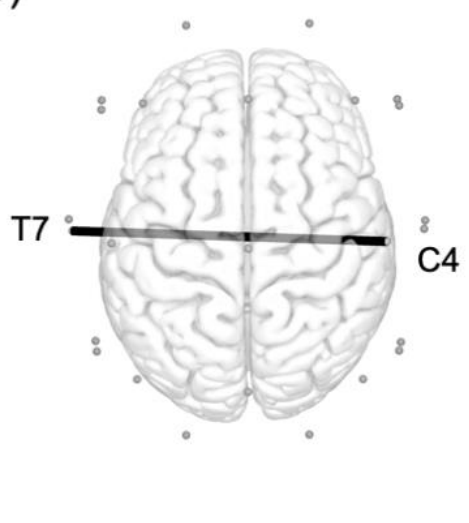

C)

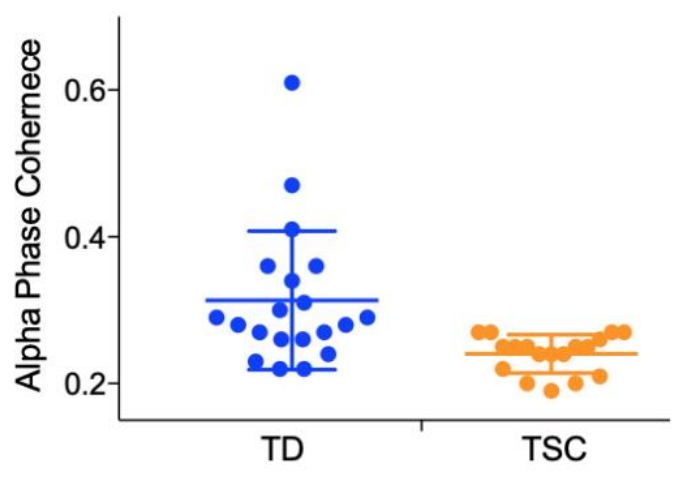

Figure 1. A) Log-transformed average power spectral density for both TSC (orange) and TD participants (blue). Shaded regions represent the median absolute deviation. B) Depiction of the interhemispheric connection that differentiated TD from TSC infants at 12 months of age (labelled connection represents significant electrode pair). C) Dot plot demonstrating APC for electrode pair T7-C4 (with group mean and error bars representing SD) for both TD and TSC groups.

\section{$A S D+/ A S D-$ group comparison}

Alpha Power: There were no power differences between ASD+ and ASD- infants at any time point (12 months P>0.10; 24 months $\mathrm{P}>0.06$ ).

PAF: At 12 months, there was no significant effect of group $(F(1,8)=1.172, P=.311)$, or region $(F(2,16)=.239, P=.790)$, and no group $x$ region interaction effect $(F(2,54)=.822, P=.457)$. At 24 months, there was no significant effect of group $(F(1$, $21)=.248, P=.624)$. There was a significant effect of region $(F(2,42)=3.549, P=.026)$, but no group $x$ region interaction effect $(F(2,42)=1.787, P=.180)$.

APC: There were no significant differences in APC between ASD+ and ASD- groups at 12 months ( $>0.003)$. Decreased long range interhemispheric $A P C$ (between electrodes T9 and $C 4$ ) was found in $A S D+(M=0.23, S D=0.03)$, compared to ASD- infants at 24 months ( $M=0.28, S D=0.04 ; P=0.00045)$. Interestingly, this is a highly similar connection to that which differentiated TSC and TD participants at 12 months.
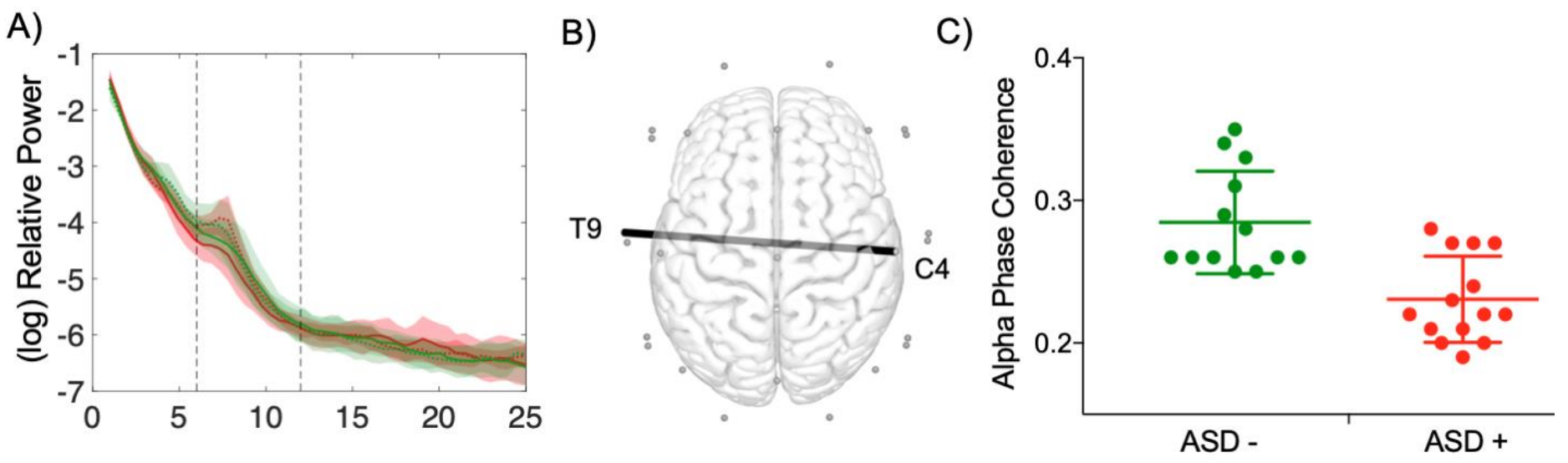

Figure 2. A) Log-transformed average power spectral density for both ASD+ (red) and ASD- participants (green). Shaded regions represent the median absolute deviation. B) Depiction of the interhemispheric connection that differentiated 
ASD+ from ASD- infants at 24 months of age (labelled connection represents significant electrode pair). C) Dot plot demonstrating APC for electrode pair T9-C4 (with group mean and error bars representing SD) for both ASD+ and ASDgroups.

Table 2. Peak alpha frequency values and group comparison results.

\begin{tabular}{|c|c|c|c|c|}
\hline & TD & TSC & Test Statistic & p-value* \\
\hline \multicolumn{5}{|l|}{ 12-Months } \\
\hline Frontal & $7.42(0.53) n=18$ & $\begin{array}{l}7.16(0.59) \\
n=16\end{array}$ & $U=102$ & .154 \\
\hline Central & $7.49(0.47) n=19$ & $7.36(.48) n=16$ & $U=124.5$ & .367 \\
\hline Occipital & $7.25(.58) n=18$ & $6.9(.63) n=16$ & $U=102.5$ & .154 \\
\hline \multicolumn{5}{|l|}{ 24-Months } \\
\hline Frontal & $8.31(.39) n=12$ & $\begin{array}{l}7.71(0.71) \\
n=27\end{array}$ & $U=75$ & $.007^{*}$ \\
\hline Central & $8.42(.44) n=12$ & $\begin{array}{l}7.8(0.87) \\
n=27\end{array}$ & $U=86$ & $.026 *$ \\
\hline Occipital & $8.08(.73) n=12$ & $\begin{array}{l}7.56(0.91) \\
n=26\end{array}$ & $U=112.5$ & .174 \\
\hline
\end{tabular}

*Represents differences between TSC and TD that remained significant after FDR correction.

\section{PAF \& Cognitive Function}

Kendall's Tau correlations were performed to test the relationships between PAF (at 12 and 24 months), and cognitive function at 36 months across the entire sample (i.e., TD and TSC). 24 month PAF across all three regions of interest was found to be positively associated with NVDQ at 36 months, and frontal and central PAF at 24 months were found to be positively associated with VDQ at 36 months.

Table 3. Associations between peak alpha frequency cognitive function across all participants.

\begin{tabular}{lll}
\hline & VDQ & NVDQ \\
\hline 12 months & $t(P)$ & $t(P)$ \\
\hline Frontal & $.013(.940)$ & $-.026(.879)$ \\
Central & $.141(.401)$ & $.211(.208)$ \\
Occipital & $.199(.234)$ & $.258(.123)$ \\
\hline 24 months & & $.420(.002)^{*}$ \\
Frontal & $.334(.013)^{*}$ & $.459(.001)^{*}$ \\
Central & $.426(<.001)^{*}$ & $.314(.020)^{*}$ \\
Occipital & $.236(.079)$ & \\
\hline
\end{tabular}

*Represents associations that remained significant after FDR correction. 

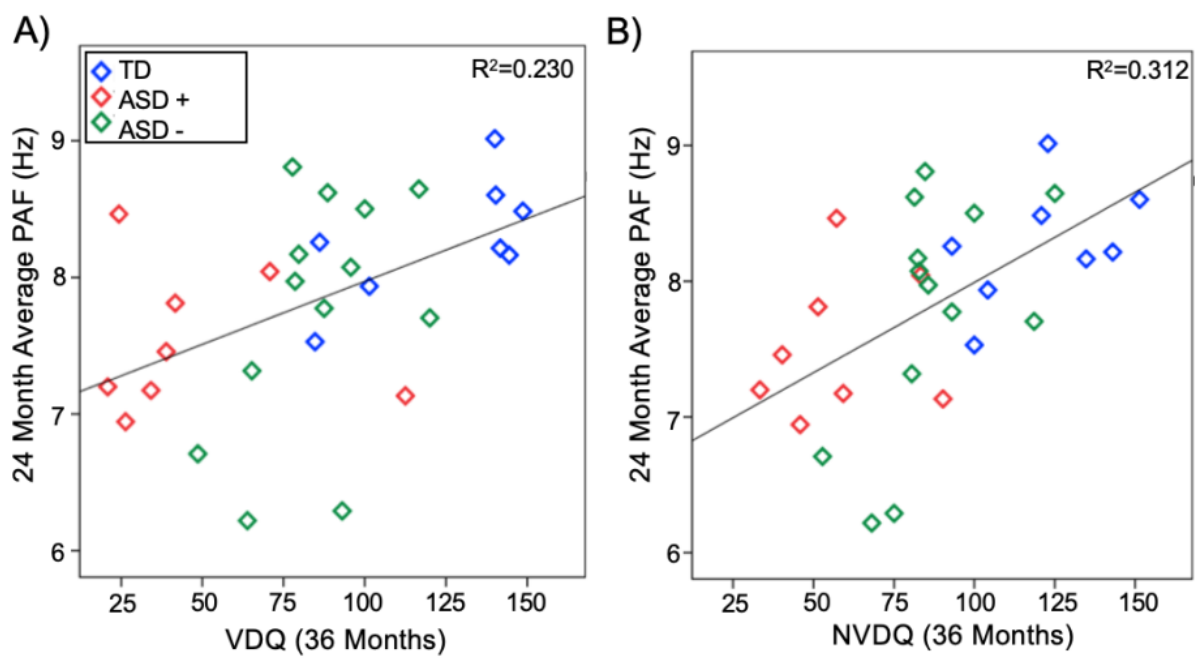

Figure 3. Scatter plots demonstrating the relationship between 24 month average PAF (averaged over frontal; central and occipital regions) and 36 months (A) VDQ, and (B) NVDQ.

\section{Discussion}

Many infants with TSC show developmental delays and emerging signs of ASD by 12 months of age, with the most robust differences occurring between 12-24 months of age (Capal et al., 2017; Jeste et al., 2014; McDonald et al., 2017). Recent evidence from older children and adults with TSC suggests that widespread alterations in neuronal connectivity may underlie the emergence of neurodevelopmental disorders in TSC (Im et al., 2015; Lewis et al., 2012; Peters et al., 2012 , 2013). The present study employed EEG measures of functional connectivity (PAF \& APC) to investigate whether network disruption is present early in life in TSC, and whether PAF and APC differentiated TSC infants who did, and did not, later receive an ASD diagnosis. We also explored whether early PAF related to later cognitive function. We expected to identify reductions in both PAF and APC during the first two years in infants with TSC. Based on previous literature describing the relationship between PAF and cognition in ASD, we also expected to find a positive association between PAF and later cognitive outcomes (Dickinson et al., 2017). This was a clinically representative cohort, with a high incidence of epilepsy and associated medications as well as cortical tuber burden, thus reinforcing the value of these EEG biomarkers even in the context of these clinical comorbidities.

\section{TSC/TD Group Comparison}

Using an unbiased, data-driven statistical approach, we found that infants with TSC demonstrate reduced interhemispheric APC between the left and right temporal regions compared to TD infants as early as 12 months of age. Notably, these differences were identified despite the absence of group differences in alpha power, suggesting that phase coherence provides increased sensitivity to functional disruptions at this early time point. In addition to APC differences, we demonstrate that PAF is consistently decreased in TSC, showing significant differences in frontal and central regions at 24 months. To the extent that APC and PAF index the development of neural networks (Wolfgang Klimesch et al., 2007; Valdés-Hernández et al., 2010), these findings suggest that functional networks show disruption from a young age in TSC.

The present findings specifically implicate aberrant long-range functional connectivity in TSC. One of the processes crucial to the integrity of large scale functional networks is the myelination of long range connections, which facilitates the efficient transfer of information over distributed brain regions (Fornari, Knyazeva, Meuli, \& Maeder, 2007). The integrity of long range structural connections is reflected in measurements of functional network properties, with oscillations in the alpha range found to be particularly reflective of changes in white matter structure (Jann et al., 2012; Picci, Gotts, \& Scherf, 2016; Teipel et al., 2009; Valdés-Hernández et al., 2010). Conversely, disorders of white matter are associated with disruptions in alpha oscillations, with decreased PAF demonstrated in vascular dementia (Moretti et al., 
2004), multiple sclerosis (Leocani et al., 2000; Tewarie et al., 2014; Van der Meer et al., 2013), and white (but not gray) matter tumors (Gloor, Kalabay, \& Giard, 1968; Goldensohn, 1979). Decreased PAF and reduced APC may therefore indicate delayed or atypical maturation of white matter during the infancy period, which is consistent with the disrupted interhemispheric white matter connections that have been identified later in TSC (Baumer et al., 2017; Im et al., 2015; Krishnan et al., 2010; Peters et al., 2012).

\section{ASD+/ASD- Group Comparison}

A strikingly similar pattern (to that differentiating TSC/TD at 12 months of age) of decreased interhemispheric connectivity emerged at 24 months in ASD+, compared to ASD- infants. This pattern is consistent with the fact that ASD is largely associated with long range decreased connectivity during childhood and adulthood (Wass, 2011), and closely resembles connectivity disturbances observed in idiopathic ASD using identical recording procedures and analyses (Dickinson et al., 2018).

The timing of differences in connectivity patterns between ASD+ and ASD- infants highlighted by the present study indicates that these changes in connectivity are not static, and likely change over development, as we would expect given the dynamic interplay of genes, environment, and clinical comorbidities that affect neural function in these infants. In fact, in other high risk infant populations, it is the change in neural connectivity over the first year of life that distinguishes infants who develop ASD from those that do not (cite IBIS, maybe just the Shen review with Piven 2017). Moreover, in nonsyndromic ASD, imaging studies have demonstrated a pattern of under-connectivity during childhood that seems to be preceded by structural over-connectivity (Wolff et al., 2012) and early cortical overgrowth (Courchesne, 2004; Courchesne \& Pierce, 2005; Hazlett et al., 2017), as well as increased functional connectivity (quantified using alpha coherence)(Orekhova et al., 2014), in the first months of life.

Therefore, it is possible that the lack of significant connectivity differences at 12 months may reflect a transitional period in the infants who go on to develop ASD (see figure 3). In nonsyndromic ASD, several neurobiological mechanisms have been attributed to underlie the atypical 'crossover' trajectory captured in ASD, including differences in axonal pruning and myelination (Wolff et al., 2015, 2012), differences in large scale anatomy (Courchesne, 2004; Hazlett et al., 2017), and a complex interplay between gray and white matter changes (Bos et al., 2015; Ecker et al., 2016). It should be noted that this is the first study to examine such change in neural function in TSC, and it supports the need for longitudinal investigation in neurodevelopmental disorders, regardless of underlying genetic etiology. Even though the impact of the TSC mutation impacts brain structure and function before birth, there are ongoing changes in the functional brain network that may be able to be modulated by early interventions (both pharmacological and behavioral). For instance, pharmacological intervention using an mTOR inhibitor, everolimus, appears to improve the microstructural integrity of the corpus callosum in patients with TSC (Peters et al., 2019; Tillema, Leach, Krueger, \& Franz, 2012).

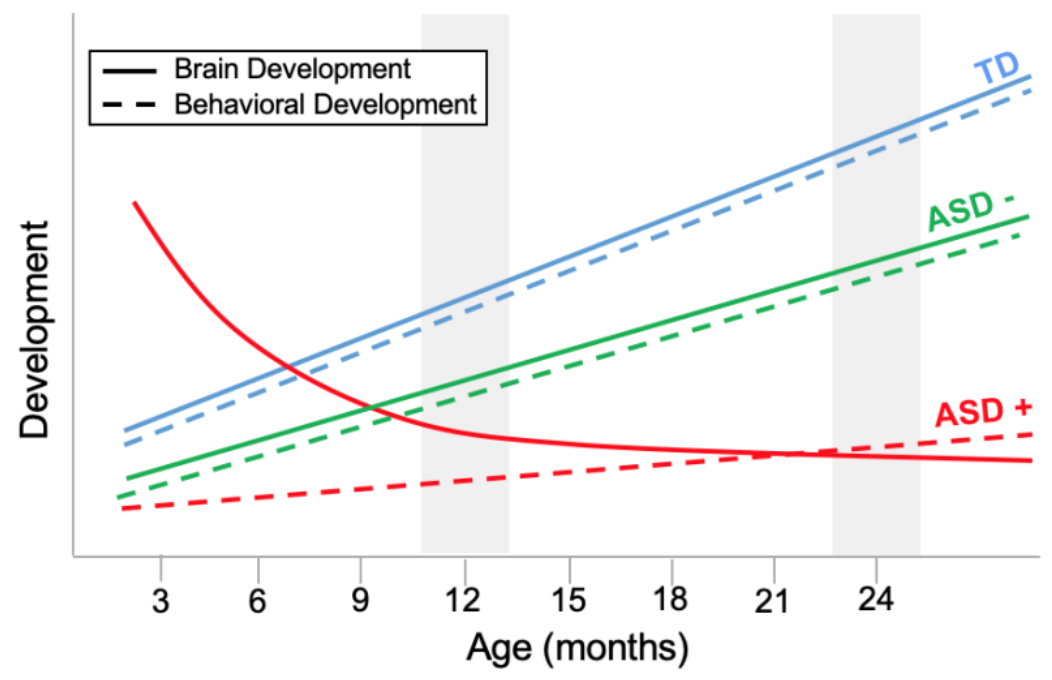


Figure 4. Theoretical (simplified) trajectories of brain and behavioral development across the first two years of life, with gray patches indicating timing of present study. Crucially, the hypothetical trajectories suggested here would elucidate why behavioral measures may discriminate ASD and no ASD in TSC at 12 months of age, but EEG measures do not.

\section{Cognition \& PAF}

Finally, we asked whether early measures of network function (PAF) related to individual differences in later clinically meaningful dimensional outcomes, which we quantified using measures of cognitive function. We found that across the entire sample, 24 month PAF was associated with cognitive functioning measured at a later timepoint (36 months). This is consistent with cross sectional work demonstrating that PAF is related to cognitive function in children with ASD (Dickinson et al., 2017), and neurotypical adults (Grandy et al., 2013; W. Klimesch, Schimke, \& Pfurtscheller, 1993; Richard Clark et al., 2004), and extends these findings to demonstrate that PAF also holds value as an early prognostic marker related to later developmental outcomes. While the limited sample size in the present study precluded withinsubgroup analyses, future studies will explore whether PAF is able to predict cognitive outcomes within (as well as across) clinical subgroups.

\section{Limitations}

Structural lesions such as cortical and subcortical hamartomas (tubers) may alter EEG measures of functional connectivity through volume conduction (Nunez \& Srinivasan, 2006; Nunez et al., 1997). We applied surface Laplacian transform in an attempt to mitigate the effects of tubers (Kayser \& Tenke, 2015). The surface Laplacian isolates the source activity under each electrode. Therefore, current source density (CSD) estimates capture the unique properties of each electrode while minimizing activity that is broadly distributed across multiple electrodes thereby reducing individual differences in volume conduction introduced through cortical differences, including tuber burden. The special consideration given to this specific signal processing issue resulted in the detection of individual differences in subgroups of TSC infants (ASD+/ASD-), two groups equivalently impacted by tuber burden.

The presence of interictal EEG abnormalities in infants with epilepsy also can alter the EEG signal being measured (Schevon et al., 2007). However, the presence of seizures is more often associated with EEG hypersynchrony (Mormann, Lehnertz, David, \& Elger, 2000; Schevon et al., 2007), which would manifest as increased phase coherence. Therefore, the fact that TSC participants in the present study show decreased phase coherence would suggest that these differences are not spuriously introduced through the presence of seizures. In addition, our goal was to include a clinically representative sample of infants with TSC, and the findings reinforce the fact that EEG biomarkers in early infancy, as in other high risk populations, hold tremendous value for early risk stratification, prediction and as possible biomarkers of change with intervention.

\section{Future Directions: APC and PAF as markers of altered neural connectivity in TSC}

The present results indicate that both APC and PAF hold utility in early life in TSC. Both of these metrics not only are able to differentiate TSC from TD infants, but are also sensitive to differences in infants who later develop ASD, and show early differences according to later cognitive function. APC and PAF have been previously associated with measures of structural network development, particularly white matter connections. In addition, a large literature of child and adult studies in TSC find disruptions in white matter integrity. Considering both of these bodies of literature, altered PAF and APC in the present study may be capturing early divergences in white matter development.

The demonstration that functional connectivity deficits in TSC can be measured as early as 12 months and relate to neurodevelopmental outcomes suggests that EEG could serve as a robust tool not only to predict seizures (which is already being done clinically) but also to inform our understanding of neurodevelopmental disorders in TSC. Future research is needed to examine functional EEG measures alongside white matter maturation in TSC in infancy in order to better understand the neurobiological mechanisms underlying early network disruption. Studying infants from earlier in life will also allow us to determine whether TSC ASD+ infants show similar patterns of long range hyperconnectivity to 
those seen during the first months of life in infants at familial risk for ASD. The in-utero diagnosis of TSC certainly facilitates this research avenue. However, due to the rare nature of TSC, and further reduction of sample sizes that occurs when comparing TSC infants based on ASD outcomes, sufficiently large samples will only be achieved through multi-site studies.

\section{Conclusions}

Here we find that EEG measures of brain network function are altered in TSC and those infants with TSC who develop ASD in the first two years of life. Specifically, we find 1) decreased long range coherence in TSC at 12 months and lower peak alpha frequency at 24 months, 2) decreased long range coherence at 12 months in infants who develop ASD, and 3) an association between peak alpha frequency and cognitive function at age 3 . The identification of objective, quantifiable markers of atypical development within the first years of life in TSC can improve the timing and accuracy of identification of those infants requiring additional, targeted developmental interventions from very early in life. The availability of scalable objective markers of altered neural development is particularly advantageous during infancy, as this is a period of peak neural plasticity during which developmental trajectories could potentially be steered. Thus, while a formidable challenge, particularly in the context of a rare disorder marked by high heterogeneity, this early detection approach is highly warranted considering the potential clinical and translational applications associated with the identification of objective (and potentially, prognostic), biological markers of neurodevelopmental outcomes.

\section{References}

Akshoomoff, N. (2006). Use of the Mullen Scales of Early Learning for the assessment of young children with Autism Spectrum Disorders. Child Neuropsychology : A Journal on Normal and Abnormal Development in Childhood and Adolescence, 12(4-5), 269-277. https://doi.org/10.1080/09297040500473714

Bateup, H. S., Johnson, C. A., Denefrio, C. L., Saulnier, J. L., Kornacker, K., \& Sabatini, B. L. (2013). Excitatory/inhibitory synaptic imbalance leads to hippocampal hyperexcitability in mouse models of tuberous sclerosis. Neuron, 78(3), 510-522.

Baumer, F. M., Peters, J. M., Clancy, S., Prohl, A. K., Prabhu, S. P., Scherrer, B., ... Stamm, A. (2017). Corpus callosum white matter diffusivity reflects cumulative neurological comorbidity in Tuberous Sclerosis Complex. Cerebral Cortex, 28(10), 3665-3672.

Baumer, F. M., Song, J. W., Mitchell, P. D., Pienaar, R., Sahin, M., Grant, P. E., \& Takahashi, E. (2015). Longitudinal changes in diffusion properties in white matter pathways of children with tuberous sclerosis complex. Pediatric Neurology, 52(6), 615-623.

Benjamini, Y., \& Hochberg, Y. (1995). Controlling the False Discovery Rate: A Practical and Powerful Approach to Multiple Testing. Journal of the Royal Statistical Society. Series B (Methodological), 57(1), 289-300.

Bos, D. J., Merchán-Naranjo, J., Martínez, K., Pina-Camacho, L., Balsa, I., Boada, L., ... Janssen, J. (2015). Reduced Gyrification Is Related to Reduced Interhemispheric Connectivity in Autism Spectrum Disorders. Journal of the American Academy of Child \& Adolescent Psychiatry, 54(8), 668-676. https://doi.org/10.1016/j.jaac.2015.05.011

Capal, J. K., Horn, P. S., Murray, D. S., Byars, A. W., Bing, N. M., Kent, B., ... Pearson, D. A. (2017). Utility of the Autism Observation Scale for infants in early identification of autism in tuberous sclerosis complex. Pediatric Neurology, 75, 80-86.

Chiang, A. K. I., Rennie, C. J., Robinson, P. A., van Albada, S. J., \& Kerr, C. C. (2011). Age trends and sex differences of alpha rhythms including split alpha peaks. Clinical Neurophysiology, 122(8), 1505-1517. https://doi.org/10.1016/j.clinph.2011.01.040

Chu-Shore, C. J., Major, P., Camposano, S., Muzykewicz, D., \& Thiele, E. A. (2010). The natural history of epilepsy in tuberous sclerosis complex. Epilepsia, 51(7), 1236-1241. https://doi.org/10.1111/j.1528-1167.2009.02474.x

Courchesne, E. (2004). Brain development in autism: Early overgrowth followed by premature arrest of growth. Mental Retardation and Developmental Disabilities Research Reviews, 10(2), 106-111. https://doi.org/10.1002/mrdd.20020

Courchesne, E., \& Pierce, K. (2005). Brain overgrowth in autism during a critical time in development: implications for frontal pyramidal neuron and interneuron development and connectivity. International Journal of 
Developmental Neuroscience: The Official Journal of the International Society for Developmental Neuroscience, 23(2-3), 153-170. https://doi.org/10.1016/j.ijdevneu.2005.01.003

Cragg, L., Kovacevic, N., McIntosh, A. R., Poulsen, C., Martinu, K., Leonard, G., \& Paus, T. (2011). Maturation of EEG power spectra in early adolescence: a longitudinal study. Developmental Science, 14(5), 935-943. https://doi.org/10.1111/j.1467-7687.2010.01031.x

Curatolo, P., Bombardieri, R., \& Jozwiak, S. (2008). Tuberous sclerosis. Lancet (London, England), 372(9639), 657-668. https://doi.org/10.1016/S0140-6736(08)61279-9

Curatolo, P., Moavero, R., \& de Vries, P. J. (2015). Neurological and neuropsychiatric aspects of tuberous sclerosis complex. The Lancet Neurology, 14(7), 733-745. https://doi.org/10.1016/S1474-4422(15)00069-1

Curatolo, P., Porfirio, M. C., Manzi, B., \& Seri, S. (2004). Autism in tuberous sclerosis. European Journal of Paediatric Neurology, 8(6), 327-332. https://doi.org/10.1016/j.ejpn.2004.08.005

Datta, A. N., Hahn, C. D., \& Sahin, M. (2008). Clinical presentation and diagnosis of tuberous sclerosis complex in infancy. Journal of Child Neurology, 23(3), 268-273.

Davis, P. E., Filip-Dhima, R., Sideridis, G., Peters, J. M., Au, K. S., Northrup, H., ... Sahin, M. (2017). Presentation and diagnosis of tuberous sclerosis complex in infants. Pediatrics, 140(6), e20164040.

Dawson, G., Klinger, L. G., Panagiotides, H., Lewy, A., \& Castelloe, P. (1995). Subgroups of autistic children based on social behavior display distinct patterns of brain activity. Journal of Abnormal Child Psychology, 23(5), 569-583. https://doi.org/10.1007/BF01447662

de Vries, P. J., Hunt, A., \& Bolton, P. F. (2007). The psychopathologies of children and adolescents with tuberous sclerosis complex (TSC). European Child \& Adolescent Psychiatry, 16(1), 16-24. https://doi.org/10.1007/s00787-0060570-3

de Vries, P. J., Whittemore, V. H., Leclezio, L., Byars, A. W., Dunn, D., Ess, K. C., ... Jansen, A. (2015). Tuberous sclerosis associated neuropsychiatric disorders (TAND) and the TAND Checklist. Pediatric Neurology, 52(1), 25-35. https://doi.org/10.1016/j.pediatrneurol.2014.10.004

Delorme, A., \& Makeig, S. (2004). EEGLAB: an open source toolbox for analysis of single-trial EEG dynamics including independent component analysis. Journal of Neuroscience Methods, 134, 9-21. https://doi.org/10.1016/j.jneumeth.2003.10.009

Devlin, L. A., Shepherd, C. H., Crawford, H., \& Morrison, P. J. (2006). Tuberous sclerosis complex: clinical features, diagnosis, and prevalence within Northern Ireland. Developmental Medicine and Child Neurology, 48(6), 495499. https://doi.org/10.1017/S0012162206001058

Dickinson, A., DiStefano, C., Lin, Y.-Y., Scheffler, A. W., Senturk, D., \& Jeste, S. S. (2018). Interhemispheric alpha-band hypoconnectivity in children with autism spectrum disorder. Behavioural Brain Research, 348, 227-234. https://doi.org/10.1016/j.bbr.2018.04.026

Dickinson, A., DiStefano, C., Senturk, D., \& Jeste, S. S. (2017). Peak alpha frequency is a neural marker of cognitive function across the autism spectrum. European Journal of Neuroscience. https://doi.org/10.1111/ejn.13645

Dustman, R. E., Shearer, D. E., \& Emmerson, R. Y. (1999). Life-span changes in EEG spectral amplitude, amplitude variability and mean frequency. Clinical Neurophysiology : Official Journal of the International Federation of Clinical Neurophysiology, 110(8), 1399-1409.

Ebrahimi-Fakhari, D., \& Sahin, M. (2015). Autism and the synapse: emerging mechanisms and mechanism-based therapies. Current Opinion in Neurology, 28(2), 91-102. https://doi.org/10.1097/WC0.0000000000000186

Ecker, C., Andrews, D., Dell'Acqua, F., Daly, E., Murphy, C., Catani, M., ... Murphy, D. G. M. (2016). Relationship Between Cortical Gyrification, White Matter Connectivity, and Autism Spectrum Disorder. Cerebral Cortex (New York, NY), 26(7), 3297-3309. https://doi.org/10.1093/cercor/bhw098

Ehninger, D., Han, S., Shilyansky, C., Zhou, Y., Li, W., Kwiatkowski, D. J., ... Silva, A. J. (2008). Reversal of learning deficits in a Tsc2+/- mouse model of tuberous sclerosis. Nature Medicine, 14(8), 843.

Ercan, E., Han, J. M., Di Nardo, A., Winden, K., Han, M.-J., Hoyo, L., ... Sahin, M. (2017). Neuronal CTGF/CCN2 negatively regulates myelination in a mouse model of tuberous sclerosis complex. Journal of Experimental Medicine, 214(3), 681-697.

Fornari, E., Knyazeva, M. G., Meuli, R., \& Maeder, P. (2007). Myelination shapes functional activity in the developing brain. Neurolmage, 38(3), 511-518. https://doi.org/10.1016/j.neuroimage.2007.07.010 
Geschwind, D. H., \& Levitt, P. (2007). Autism spectrum disorders: developmental disconnection syndromes. Current Opinion in Neurobiology, 17(1), 103-111. https://doi.org/10.1016/j.conb.2007.01.009

Gloor, P., Kalabay, O., \& Giard, N. (1968). THE ELECTROENCEPHALOGRAM IN DIFFUSE ENCEPHALOPATHIES: ELECTROENCEPHALOGRAPHIC CORRELATES OF GREY AND WHITE MATTER LESIONS. Brain, 91(4), 779-802. https://doi.org/10.1093/brain/91.4.779

Goldensohn, E. S. (1979). Use of EEG for Evaluation of Focal Intracranial Lesions. In Current Practice of Clinical Electroencephalography (pp. 307-341). Raven.

Gotham, K., Risi, S., Pickles, A., \& Lord, C. (2007). The Autism Diagnostic Observation Schedule: Revised Algorithms for Improved Diagnostic Validity. Journal of Autism and Developmental Disorders, 37(4), 613-627. https://doi.org/10.1007/s10803-006-0280-1

Granader, Y. E., Bender, H. A., Zemon, V., Rathi, S., Nass, R., \& MacAllister, W. S. (2010). The clinical utility of the Social Responsiveness Scale and Social Communication Questionnaire in tuberous sclerosis complex. Epilepsy \& Behavior, 18(3), 262-266. https://doi.org/10.1016/j.yebeh.2010.04.010

Grandy, T. H., Werkle-Bergner, M., Chicherio, C., Lövdén, M., Schmiedek, F., \& Lindenberger, U. (2013). Individual alpha peak frequency is related to latent factors of general cognitive abilities. Neurolmage, 79, 10-18. https://doi.org/10.1016/j.neuroimage.2013.04.059

Gudmundsson, S., Runarsson, T. P., Sigurdsson, S., Eiriksdottir, G., \& Johnsen, K. (2007). Reliability of quantitative EEG features. Clinical Neurophysiology, 118(10), 2162-2171. https://doi.org/10.1016/j.clinph.2007.06.018

Guggisberg, A. G., Honma, S. M., Findlay, A. M., Dalal, S. S., Kirsch, H. E., Berger, M. S., \& Nagarajan, S. S. (2008). Mapping Functional Connectivity in Patients with Brain Lesions. Annals of Neurology, 63(2), 193-203. https://doi.org/10.1002/ana.21224

Hazlett, H. C., Gu, H., Munsell, B. C., Kim, S. H., Styner, M., Wolff, J. J., ... Statistical Analysis. (2017). Early brain development in infants at high risk for autism spectrum disorder. Nature, 542(7641), 348-351. https://doi.org/10.1038/nature21369

Hinkley, L. B. N., Vinogradov, S., Guggisberg, A. G., Fisher, M., Findlay, A. M., \& Nagarajan, S. S. (2011). Clinical Symptoms and Alpha Band Resting-State Functional Connectivity Imaging in Patients With Schizophrenia: Implications for Novel Approaches to Treatment. Biological Psychiatry, 70(12), 1134-1142. https://doi.org/10.1016/j.biopsych.2011.06.029

Im, K., Ahtam, B., Haehn, D., Peters, J. M., Warfield, S. K., Sahin, M., \& Ellen Grant, P. (2015). Altered structural brain networks in tuberous sclerosis complex. Cerebral Cortex, 26(5), 2046-2058.

Jann, K., Federspiel, A., Giezendanner, S., Andreotti, J., Kottlow, M., Dierks, T., \& Koenig, T. (2012). Linking Brain Connectivity Across Different Time Scales with Electroencephalogram, Functional Magnetic Resonance Imaging, and Diffusion Tensor Imaging. Brain Connectivity, 2(1), 11-20. https://doi.org/10.1089/brain.2011.0063

Jasper, H. (1958). The ten twenty electrode system of the international federation. Electroencephalography and Clinical Neuroph Siology, 10, 371-375.

Jeste, S. S., Frohlich, J., \& Loo, S. K. (2015). Electrophysiological biomarkers of diagnosis and outcome in neurodevelopmental disorders. Current Opinion in Neurology, 28(2), 110. https://doi.org/10.1097/WCO.0000000000000181

Jeste, S. S., Sahin, M., Bolton, P., Ploubidis, G. B., \& Humphrey, A. (2008). Characterization of Autism in Young Children With Tuberous Sclerosis Complex. Journal of Child Neurology, 23(5), 520-525. https://doi.org/10.1177/0883073807309788

Jeste, S. S., Varcin, K. J., Hellemann, G. S., Gulsrud, A. C., Bhatt, R., Kasari, C., ... Nelson, C. A. (2016). Symptom profiles of autism spectrum disorder in tuberous sclerosis complex. Neurology, 87(8), 766-772.

Jeste, S. S., Wu, J. Y., Senturk, D., Varcin, K., Ko, J., McCarthy, B., ... Sahin, M. (2014). Early developmental trajectories associated with ASD in infants with tuberous sclerosis complex. Neurology, 83(2), 160-168.

Joinson, C., O'Callaghan, F. J., Osborne, J. P., Martyn, C., Harris, T., \& Bolton, P. F. (2003). Learning disability and epilepsy in an epidemiological sample of individuals with tuberous sclerosis complex. Psychological Medicine, 33(2), 335344.

Jülich, K., \& Sahin, M. (2014). Mechanism-based treatment in tuberous sclerosis complex. Pediatric Neurology, 50(4), 290-296. 
Kayser, J., \& Tenke, C. E. (2015). On the benefits of using surface Laplacian (Current Source Density) methodology in electrophysiology. International Journal of Psychophysiology: Official Journal of the International Organization of Psychophysiology, 97(3), 171-173. https://doi.org/10.1016/j.ijpsycho.2015.06.001

Kida, T., Tanaka, E., \& Kakigi, R. (2016). Multi-Dimensional Dynamics of Human Electromagnetic Brain Activity. Frontiers in Human Neuroscience, 9, 713-713. https://doi.org/10.3389/fnhum.2015.00713

Klimesch, W., Schimke, H., \& Pfurtscheller, G. (1993). Alpha frequency, cognitive load and memory performance. Brain Topography, 5(3), 241-251. https://doi.org/10.1007/BF01128991

Klimesch, Wolfgang, Sauseng, P., \& HansImayr, S. (2007). EEG alpha oscillations: The inhibition-timing hypothesis. Brain Research Reviews, 53(1), 63-88. https://doi.org/10.1016/j.brainresrev.2006.06.003

Knox, S., Ge, H., Dimitroff, B. D., Ren, Y., Howe, K. A., Arsham, A. M., ... Selleck, S. B. (2007). Mechanisms of TSCmediated control of synapse assembly and axon guidance. PloS One, 2(4), e375.

Krishnan, M. L., Commowick, O., Jeste, S. S., Weisenfeld, N., Hans, A., Gregas, M. C., ... Warfield, S. K. (2010). Diffusion Features of White Matter in Tuberous Sclerosis With Tractography. Pediatric Neurology, 42(2), 101-106. https://doi.org/10.1016/j.pediatrneurol.2009.08.001

Leclezio, L., Jansen, A., Whittemore, V. H., \& de Vries, P. J. (2015). Pilot validation of the tuberous sclerosis-associated neuropsychiatric disorders (TAND) checklist. Pediatric Neurology, 52(1), 16-24. https://doi.org/10.1016/j.pediatrneurol.2014.10.006

Leocani, L., Locatelli, T., Martinelli, V., Rovaris, M., Falautano, M., Filippi, M., ... Comi, G. (2000). Electroencephalographic coherence analysis in multiple sclerosis: correlation with clinical, neuropsychological, and MRI findings. Journal of Neurology, Neurosurgery, and Psychiatry, 69(2), 192-198.

Lewis, W. W., Sahin, M., Scherrer, B., Peters, J. M., Suarez, R. O., Vogel-Farley, V. K., ... Nelson III, C. A. (2012). Impaired language pathways in tuberous sclerosis complex patients with autism spectrum disorders. Cerebral Cortex, 23(7), 1526-1532.

Lord, C., Risi, S., Lambrecht, L., Cook, E. H., Leventhal, B. L., DiLavore, P. C., ... Rutter, M. (2000). The autism diagnostic observation schedule-generic: a standard measure of social and communication deficits associated with the spectrum of autism. Journal of Autism and Developmental Disorders, 30(3), 205-223.

Makeig, S., Jung, T. P., Bell, A. J., Ghahremani, D., \& Sejnowski, T. J. (1997). Blind separation of auditory event-related brain responses into independent components. Proceedings of the National Academy of Sciences of the United States of America, 94(20), 10979-10984. https://doi.org/10.1073/PNAS.94.20.10979

McDonald, N. M., Varcin, K. J., Bhatt, R., Wu, J. Y., Sahin, M., Nelson, C. A., \& Jeste, S. S. (2017). Early autism symptoms in infants with tuberous sclerosis complex. Autism Research, 10(12), 1981-1990. https://doi.org/10.1002/aur.1846

McEvoy, K., Hasenstab, K., Senturk, D., Sanders, A., \& Jeste, S. S. (2015). Physiologic artifacts in resting state oscillations in young children: methodological considerations for noisy data. Brain Imaging and Behavior, 9(1), 104-114. https://doi.org/10.1007/s11682-014-9343-7

McLaughlin, K. A., Fox, N. A., Zeanah, C. H., \& Nelson, C. A. (2011). Adverse Rearing Environments and Neural Development in Children: The Development of Frontal Electroencephalogram Asymmetry. Biological Psychiatry, 70(11), 1008-1015. https://doi.org/10.1016/j.biopsych.2011.08.006

Miskovic, V., Ma, X., Chou, C.-A., Fan, M., Owens, M., Sayama, H., \& Gibb, B. E. (2015). Developmental changes in spontaneous electrocortical activity and network organization from early to late childhood. Neurolmage, 118, 237-247. https://doi.org/10.1016/j.neuroimage.2015.06.013

Moretti, D. V., Babiloni, C., Binetti, G., Cassetta, E., Dal Forno, G., Ferreric, F., ... Rossini, P. M. (2004). Individual analysis of EEG frequency and band power in mild Alzheimer's disease. Clinical Neurophysiology: Official Journal of the International Federation of Clinical Neurophysiology, 115(2), 299-308.

Mormann, F., Lehnertz, K., David, P., \& Elger, C. (2000). Mean phase coherence as a measure for phase synchronization and its application to the EEG of epilepsy patients. Physica D: Nonlinear Phenomena, 144, 358-369. https://doi.org/10.1016/S0167-2789(00)00087-7

Mullen, E. M. (1995). Mullen scales of early learning. Retrieved from http://www.v-psyche.com/doc/specialcases/Mullen Scales of Early Learning.docx

Neto, E., Allen, E. A., Aurlien, H., Nordby, H., \& Eichele, T. (2015). EEG Spectral Features Discriminate between Alzheimer's and Vascular Dementia. Frontiers in Neurology, 6, 25. https://doi.org/10.3389/fneur.2015.00025 
Nie, D., Di Nardo, A., Han, J. M., Baharanyi, H., Kramvis, I., Huynh, T., ... Pasquale, E. B. (2010). Tsc2-Rheb signaling regulates EphA-mediated axon guidance. Nature Neuroscience, 13(2), 163.

Northrup, H., Krueger, D. A., \& International Tuberous Sclerosis Complex Consensus Group. (2013). Tuberous sclerosis complex diagnostic criteria update: recommendations of the 2012 linternational Tuberous Sclerosis Complex Consensus Conference. Pediatric Neurology, 49(4), 243-254. https://doi.org/10.1016/j.pediatrneurol.2013.08.001

Nunez, P. L., \& Srinivasan, R. (2006). A theoretical basis for standing and traveling brain waves measured with human EEG with implications for an integrated consciousness. Clinical Neurophysiology, 117(11), 2424-2435.

Nunez, P. L., Srinivasan, R., Westdorp, A. F., Wijesinghe, R. S., Tucker, D. M., Silberstein, R. B., \& Cadusch, P. J. (1997). EEG coherency: I: statistics, reference electrode, volume conduction, Laplacians, cortical imaging, and interpretation at multiple scales. Electroencephalography and Clinical Neurophysiology, 103(5), 499-515.

Oberman, L. M., Ramachandran, V. S., \& Pineda, J. A. (2008). Modulation of mu suppression in children with autism spectrum disorders in response to familiar or unfamiliar stimuli: The mirror neuron hypothesis. Neuropsychologia, 46(5), 1558-1565. https://doi.org/10.1016/j.neuropsychologia.2008.01.010

Orekhova, E. V., Elsabbagh, M., Jones, E. J., Dawson, G., Charman, T., Johnson, M. H., \& BASIS Team, T. B. (2014). EEG hyper-connectivity in high-risk infants is associated with later autism. Journal of Neurodevelopmental Disorders, 6(1), 40-40. https://doi.org/10.1186/1866-1955-6-40

Peters, J. M., Prohl, A., Kapur, K., Nath, A., Scherrer, B., Clancy, S., ... Krueger, D. A. (2019). Longitudinal Effects of Everolimus on White Matter Diffusion in Tuberous Sclerosis Complex. Pediatric Neurology, 90, 24-30. https://doi.org/10.1016/j.pediatrneurol.2018.10.005

Peters, J. M., Sahin, M., Vogel-Farley, V. K., Jeste, S. S., Nelson III, C. A., Gregas, M. C., ... Warfield, S. K. (2012). Loss of white matter microstructural integrity is associated with adverse neurological outcome in tuberous sclerosis complex. Academic Radiology, 19(1), 17-25.

Peters, J. M., Taquet, M., Vega, C., Jeste, S. S., Fernández, I. S., Tan, J., ... Warfield, S. K. (2013). Brain functional networks in syndromic and non-syndromic autism: a graph theoretical study of EEG connectivity. BMC Medicine, 11(1), 54.

Picci, G., Gotts, S. J., \& Scherf, K. S. (2016). A theoretical rut: revisiting and critically evaluating the generalized under/over-connectivity hypothesis of autism. Developmental Science, 19(4), 524-549.

Richard Clark, C., Veltmeyer, M. D., Hamilton, R. J., Simms, E., Paul, R., Hermens, D., \& Gordon, E. (2004). Spontaneous alpha peak frequency predicts working memory performance across the age span. International Journal of Psychophysiology, 53(1), 1-9. https://doi.org/10.1016/j.ijpsycho.2003.12.011

Roth, J., Roach, E. S., Bartels, U., Jóźwiak, S., Koenig, M. K., Weiner, H. L., ... Wang, H. Z. (2013). Subependymal giant cell astrocytoma: diagnosis, screening, and treatment. Recommendations from the International Tuberous Sclerosis Complex Consensus Conference 2012. Pediatric Neurology, 49(6), 439-444.

https://doi.org/10.1016/j.pediatrneurol.2013.08.017

Saby, J. N., \& Marshall, P. J. (2012). The Utility of EEG Band Power Analysis in the Study of Infancy and Early Childhood. Developmental Neuropsychology, 37(3), 253-273. https://doi.org/10.1080/87565641.2011.614663

Schevon, C. A., Cappell, J., Emerson, R., Isler, J., Grieve, P., Goodman, R., ... Gilliam, F. (2007). Cortical abnormalities in epilepsy revealed by local EEG synchrony. Neurolmage, 35(1), 140-148. https://doi.org/10.1016/j.neuroimage.2006.11.009

Smit, D. J. A., Boersma, M., Schnack, H. G., Micheloyannis, S., Boomsma, D. I., Hulshoff Pol, H. E., ... de Geus, E. J. C. (2012). The Brain Matures with Stronger Functional Connectivity and Decreased Randomness of Its Network. PLOS ONE, 7(5), e36896-e36896. https://doi.org/10.1371/journal.pone.0036896

Somsen, R. J., van't Klooster, B. J., van der Molen, M. W., van Leeuwen, H. M., \& Licht, R. (1997). Growth spurts in brain maturation during middle childhood as indexed by EEG power spectra. Biological Psychology, 44(3), 187-209.

Stroganova, T. A., Orekhova, E. V., \& Posikera, I. N. (1999). EEG alpha rhythm in infants. Clinical Neurophysiology: Official Journal of the International Federation of Clinical Neurophysiology, 110(6), 997-1012.

Teipel, S. J., Pogarell, O., Meindl, T., Dietrich, O., Sydykova, D., Hunklinger, U., ... Hampel, H. (2009). Regional networks underlying interhemispheric connectivity: an EEG and DTI study in healthy ageing and amnestic mild cognitive impairment. Human Brain Mapping, 30(7), 2098-2119. https://doi.org/10.1002/hbm.20652 
Tewarie, P., Hillebrand, A., Schoonheim, M. M., van Dijk, B. W., Geurts, J. J. G., Barkhof, F., ... Stam, C. J. (2014). Functional brain network analysis using minimum spanning trees in Multiple Sclerosis: An MEG source-space study. Neurolmage, 88, 308-318. https://doi.org/10.1016/j.neuroimage.2013.10.022

Tierney, A. L., Gabard-Durnam, L., Vogel-Farley, V., Tager-Flusberg, H., \& Nelson, C. A. (2012). Developmental Trajectories of Resting EEG Power: An Endophenotype of Autism Spectrum Disorder. PLoS ONE, 7(6), e39127. https://doi.org/10.1371/journal.pone.0039127

Tillema, J.-M., Leach, J. L., Krueger, D. A., \& Franz, D. N. (2012). Everolimus alters white matter diffusion in tuberous sclerosis complex. Neurology, 78(8), 526-531.

Valdés-Hernández, P. A., Ojeda-González, A., Martínez-Montes, E., Lage-Castellanos, A., Virués-Alba, T., Valdés-Urrutia, L., \& Valdes-Sosa, P. A. (2010). White matter architecture rather than cortical surface area correlates with the EEG alpha rhythm. Neurolmage, 49(3), 2328-2339. https://doi.org/10.1016/j.neuroimage.2009.10.030

Van der Meer, M. L., Tewarie, P., Schoonheim, M. M., Douw, L., Barkhof, F., Polman, C. H., ... Hillebrand, A. (2013). Cognition in MS correlates with resting-state oscillatory brain activity: An explorative MEG source-space study. Neurolmage : Clinical, 2, 727-734. https://doi.org/10.1016/j.nicl.2013.05.003

Vignoli, A., La Briola, F., Peron, A., Turner, K., Vannicola, C., Saccani, M., ... Canevini, M. P. (2015). Autism spectrum disorder in tuberous sclerosis complex: searching for risk markers. Orphanet Journal of Rare Diseases, 10, 154. https://doi.org/10.1186/s13023-015-0371-1

Wass, S. (2011). Distortions and disconnections: Disrupted brain connectivity in autism. Brain and Cognition, 75(1), 1828. https://doi.org/10.1016/j.bandc.2010.10.005

Webb, S. J., Bernier, R., Henderson, H. A., Johnson, M. H., Jones, E. J. H., Lerner, M. D., ... Westerfield, M. (2015). Guidelines and best practices for electrophysiological data collection, analysis and reporting in autism. Journal of Autism and Developmental Disorders, 45(2), 425-443. https://doi.org/10.1007/s10803-013-1916-6

Wolff, J. J., Gerig, G., Lewis, J. D., Soda, T., Styner, M. A., Vachet, C., ... IBIS Network. (2015). Altered corpus callosum morphology associated with autism over the first 2 years of life. Brain: A Journal of Neurology, 138(Pt 7), 20462058. https://doi.org/10.1093/brain/awv118

Wolff, J. J., Gu, H., Gerig, G., Elison, J. T., Styner, M., Gouttard, S., ... IBIS Network. (2012). Differences in White Matter Fiber Tract Development Present From 6 to 24 Months in Infants With Autism. American Journal of Psychiatry, 169(6), 589-600. https://doi.org/10.1176/appi.ajp.2011.11091447

Zeng, L.-H., Ouyang, Y., Gazit, V., Cirrito, J. R., Jansen, L. A., Ess, K. C., ... Gutmann, D. H. (2007). Abnormal glutamate homeostasis and impaired synaptic plasticity and learning in a mouse model of tuberous sclerosis complex. Neurobiology of Disease, 28(2), 184-196.

\section{Conflict of Interest}

S.S.J. serves as a consultant for Roche Pharmaceuticals and on the professional advisory board for the Tuberous Sclerosis Alliance. M.S. receives research support from Novartis, Roche, Pfizer, LAM Therapeutics and Quadrant Biosciences, and has served on the Scientific Advisory Board of Sage Therapeutics, Roche, Celegne and Takeda. The remaining authors (A.D, K.J.V., C.A.N.) do not have any conflicts of interest associated with this study. 